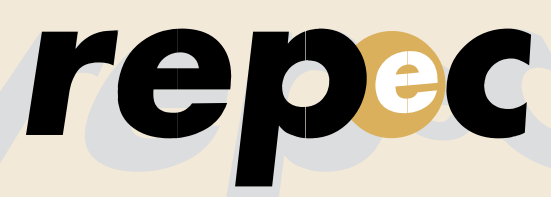

REPeC, Brasília, v. 10, n. 3, art. 3, p. 272-288, jul./set. 2016

Disponivel online em www.repec.org.br

DOl: http://dx.doi.org/10.17524/repec.v10i3.1361
Revista de Educação e Pesquisa em Contabilidade

Journal of Education and Research in Accounting

Periódico Trimestral, digital e gratuito publicado pela Academia Brasileira de Ciências Contábeis

ISSN 1981-8610

\title{
Fatores Determinantes para Adoção de Planos de Opções de Ações em Companhias Abertas Brasileiras
}

\begin{abstract}
Resumo
O objetivo do estudo foi identificar os fatores determinantes para adoção de planos de opções de ações em companhias abertas brasileiras. Para tal, realizou-se pesquisa descritiva, conduzida por meio de análise documental e abordagem quantitativa, com emprego de regressão logística. A amostra foi composta de 158 companhias, com dados referentes ao período de 2009 a 2012. Os resultados evidenciaram um crescimento na quantidade de empresas que possuíam planos de opções de ações no período. Entre os fatores tamanho da empresa, restrição de liquidez, concentração acionária, problema de horizonte, participação acionária do $\mathrm{CEO}$, dualidade do cargo de $\mathrm{CEO}$ e presidente do conselho de administração, descritos na literatura como influenciadores para a utilização de planos de opções de ações, três se confirmaram na amostra analisada. Os fatores "liquidez corrente", no período de 2010 a 2012; "problema de horizonte", no período de 2009 a 2012; e "participação acionária", no ano de 2012, fornecem mais evidências de relações positivas no cenário brasileiro.
\end{abstract}

Palavras-chave: Fatores determinantes; Adoção de planos de opções de ações; Companhias abertas brasileiras.
Geovanne Dias de Moura

Doutor em Ciências Contábeis e Administração pela Universidade Regional de Blumenau (Furb) e Professor do Programa de Pós-Graduação em Ciências Contábeis e Administração da Universidade Comunitária da Região de Chapecó - Unochapecó. Contato: Avenida Senador Attílio Fontana, 591-E. Bairro: EFAPI. Chapecó-SC, CEP: : 89.809-000. E-mail: geomoura@terra.com.br

\section{Edilson Sidnei Padilha}

Mestre em Ciências Contábeis pela Universidade Regional de Blumenau (Furb) e Professor do Curso de Ciências Contábeis/Administração - Coordenador do Curso de Ciências Contábeis - Coordenador de Programa de PósGraduação em Ciências Contábeis - no Centro Universitário de Brusque - Unifebe. Contato: Rua Dorval Luz, 123, bloco E NAC. Bairro: Santa Terezinha. Brusque-SC, CEP: 88352-400.

E-mail: edilsonpadilha@terra.com.br

\section{Tarcísio Pedro da Silva}

Doutor em Ciências Contábeis e

Administração pela Universidade Regional de Blumenau (Furb) e Professor do Programa de Pós-Graduação em Ciências Contábeis da Universidade Regional de Blumenau (Furb). Contato: Rua Antônio da Veiga, 140. Bairro: Victor Konder. Blumenau-SC, CEP: 89.030-930. E-mail: tarcisio@furb.br 


\section{Introdução}

Entre as possibilidades de remuneração existentes, os planos de opções de ações são uma das formas de incentivo de longo prazo mais utilizadas nos Estados Unidos e Europa. Essa alternativa de remuneração, aos poucos, se difunde também no Brasil, principalmente sob o argumento de que a participação acionária dos gestores representa um método direto e eficiente para alinhar interesses entre proprietário e gestor (Wood \& Picarelli, 2004; Galdi \& Carvalho, 2006; Dias, Cunha \& Mário, 2009; Cesari \& Ozkan, 2015).

Os conflitos ocasionados pela separação de propriedade e gestão são tratados pela teoria da Agência, que teve como precursores Jensen e Meckling (1976), em um estudo no qual citam que a teoria da Agência examina as relações entre principais e agentes. Apesar de o agente (gestor), em princípio, trabalhar para o principal (acionista), ele acaba criando suas motivações pessoais e seus próprios objetivos de maximização de satisfação, que nem sempre estão alinhados aos do principal.

Nesse sentido, Galdi e Carvalho (2006) mencionam que a adoção de planos de opções de ações, teoricamente, diminui conflitos de agência, em virtude de o empregado ter como meta a maximização do valor da empresa para, assim, aumentar também sua remuneração. Em inúmeras pesquisas relacionadas a planos de opções de ações, como, por exemplo, Ding e Sun (2001), Uchida (2006), Tzioumis (2008), Dias (2010), Perobelli, Lopes e Silveira (2012), Quin (2012) e Cesari e Ozkan (2015), a ênfase encontra-se nos problemas de agência causados pela separação da propriedade e do controle em grandes corporações.

Além disso, pesquisadores (Bryan, Hwang \& Lilien, 2000; Uchida, 2006; Tzioumis, 2008; Dias, 2010; Qin, 2012) também apontam que a crescente utilização de planos de opções de ações pode estar associada a diversos fatores. No entanto, no Brasil, onde o interesse pela pesquisa desse tema é crescente, a investigação dos fatores determinantes ainda se constitui em lacuna de pesquisa relevante, pois a maioria das pesquisas concentraram-se em questões relacionadas à divulgação das informações referentes aos planos de opções de ações. Como exemplos, podem ser citados os estudos de Nunes (2008), Dias et al. (2009), Perobelli et al. (2012), Miranda, Tomé e Gallon (2011), Niyama, Campos, Gonçalves e Campos (2012), Tannuri, Farias, Vicente, Bellen e Alberton (2012) e Larini, Schäfer, Rosa e Ferreira (2015).

$\mathrm{Na}$ literatura, dentre os fatores determinantes para a adoção de opções de ações, destacam-se o tamanho da empresa (Ding \& Sun, 2001; Kato, Lemmon, Luo \& Schallheim, 2005; Uchida, 2006; Chourou, Abaoub \& Saadi, 2008; Tzioumis, 2008; Dias, 2010); restrições de liquidez (Yermack, 1995; Bryan et al., 2000; Ding \& Sun, 2001; Uchida, 2006; Tzioumis, 2008; Dias, 2010); concentração acionária (Nagaoka, 2005; Banghoj, Gabrielsen, Petersen \& Plenborg, 2010; Dias, 2010); problema de horizonte (Bryan et al., 2000; Tzioumis, 2008); dualidade do cargo de CEO e presidente do conselho de administração (TZIOUMIS, 2008; QIN, 2012); e participação acionária do CEO (Kato et al., 2005; Uchida, 2006; Chourou et al., 2008; Tzioumis, 2008; Qin, 2012).

Com base no exposto, elaborou-se a pergunta de pesquisa que orienta este estudo: Quais são os fatores determinantes para a adoção de planos de opções de ações em companhias abertas brasileiras? Assim, este estudo objetiva identificar os fatores determinantes para a adoção de planos de opções de ações em companhias abertas brasileiras.

O estudo justifica-se em virtude da importância do tema frente ao problema de agência nas empresas e devido a divergências constatadas em resultados de pesquisas anteriores (Bryan et al., 2000; Ding \& Sun, 2001; Kato et al., 2005; Uchida, 2006; Tzioumis, 2008; Dias, 2010; Qin, 2012), de mesma natureza, e que geram inquietações. Ressalta-se que os resultados não são conclusivos quanto aos efeitos de cada variável, uma vez que, na maioria dos casos, as variáveis apresentam resultados divergentes entre as pesquisas (Dias, 2010).

Ainda, pelo reduzido número de estudos no contexto do mercado brasileiro, cabe destacar, novamente, que a investigação dos fatores determinantes para a utilização dessa forma de remuneração variável ainda se constitui em lacuna de pesquisa relevante no mercado de ações brasileiro, haja vista que, no Brasil, foram analisadas, principalmente, questões relacionadas à divulgação das informações referentes aos planos de opções de ações. Então, pretende-se contribuir para a ampliação da discussão em torno da temática. 
A relevância do estudo pode ser percebida, também, no fato de ele relacionar a adoção de planos de opções de ações com fatores pouco explorados por pesquisadores brasileiros, mas já apontados na literatura internacional. Dessa forma, o estudo justifica-se, pois contribui para fortalecer o entendimento sobre o tema no cenário brasileiro e estende a discussão relacionada aos fatores que podem influenciar a adoção de planos de opções de ações.

O estudo está estruturado em sete seções, iniciando-se com essa introdução. Em seguida, apresenta-se o referencial teórico, que aborda conteúdos sobre teoria da agência, planos de opções de ações e fatores determinantes para adoção de planos de opções de ações. Após, são descritos os aspectos metodológicos utilizados para o desenvolvimento da pesquisa. Em seguida, faz-se a descrição e a análise dos resultados; e, por último, apresentam-se as considerações finais do estudo.

\section{Teoria da Agência}

A teoria da Agência foi introduzida na economia na década de 1970, por conta da partilha de riscos entre principais e agentes, haja vista que muitas vezes diretores e agentes trabalham juntos, mas com propósitos diferentes (Jensen \& Meckling, 1976). O risco era tratado de maneira diferente pelas partes envolvidas. Dessa forma, a teoria da Agência ampliou os estudos acerca da temática de riscos, incluindo o chamado problema de agência, que ocorre quando partes cooperantes têm objetivos diferentes e divisão do trabalho (Ross, 1973; Jensen \& Meckling, 1976).

Nas relações de agência, dois problemas podem ocorrer: os objetivos do principal conflitarem com os do agente e ser dispendioso para o principal verificar o que o agente está realmente fazendo; e a partilha do risco, que surge quando o principal e o agente têm diferentes atitudes em relação ao risco (Jensen \& Meckling, 1976).

Quando o principal está ciente das atividades do agente, um sistema de remuneração baseado em comportamento pode ser eficaz. Quando o diretor não sabe o que o agente está fazendo, o conflito pode ocorrer. Na teoria da Agência, os conflitos entre o principal e o agente são conhecidos como risco moral e seleção adversa (Fama \& Jensen, 1983). O problema de risco moral pode ser entendido como ações ocultas aos proprietários ou custosas de se observarem. O problema de seleção adversa pode ser considerado como informações ocultas - nesse caso, o agente possui informações que, aos proprietários, são inobserváveis (Arrow, 1985).

No momento em que se delega trabalho do principal para o agente, a relação de agência se desenvolve. A missão do agente é a de realizar perfeitamente os interesses do principal. Este tem um risco de eventual fracasso, mas também adota efeitos da execução do agente da missão reduzida para pagamento acordado com o agente. Dessa forma, o nível de recompensa para o agente, geralmente, depende de interesse do diretor de realização da missão atribuída. A vantagem para o agente, na forma de recompensa, representa custo para o principal, enquanto o esforço do agente traz benefícios para o principal e, ao mesmo tempo, custo para o agente (Eisenhardt, 1989).

Acredita-se que a teoria da Agência desenvolva fatores de monitoramento e de partilha de riscos, afetando um sistema de remuneração com base no desempenho do agente. Fatores de monitoramento incluem programação de trabalho, o investimento em sistemas de seleção, monitoramento de desempenho pelo comitente e a proximidade relacional principal-agente. Esses fatores de risco consistem em atitudes dos principais e dos agentes em relação ao risco, o tamanho da compra e incerteza no resultado do desempenho (Eisenhardt, 1989; Bergen, Dutta \& Walker, 1992).

A teoria da Agência é utilizada a fim de analisar o conflito de interesses entre as principais partes interessadas, além do desenvolvimento de mecanismos de resolução de conflitos (Tipuric, 2008). Os agentes são motivados pelo autointeresse e são atores racionais. Assim sendo, os diretores podem motivar os agentes controlando seus incentivos. Os sistemas de informações proíbem o oportunismo do agente, uma vez que informam o diretor sobre o que o agente pode fazer. Quando a entidade tem informações para verificar o comportamento do agente, o agente é mais propenso a se comportar em favor dos interesses do principal (Eisenhardt, 1989). 
De acordo com Siffert (1996), as relações bilaterais entre o principal e o agente têm três características comuns: (a) o agente dispõe de várias ações, podendo empregar os recursos da empresa de distintas maneiras, até mesmo se apropriando indevidamente de parte desse montante ou, simplesmente, não o aplicando, de forma a maximizar o lucro dos sócios; (b) o comportamento dos agentes afeta não apenas seu próprio bem-estar, mas também o do principal, seja pelo aumento ou redução dos recursos financeiros disponíveis, afetando o desempenho da organização; e (c) há assimetria informacional entre as partes. Não é possível ao principal monitorar todos os passos do agente, tampouco identificar seu grau de compromisso em trabalhar para maximizar o bem-estar do principal.

O contrato ótimo entre principal e agente faz parte das discussões formuladas na teoria de Agência, em que o agente (gerente ou funcionário) tenta maximizar os ganhos pessoais por objetivos econômicos do principal de forma satisfatória, e o nível de comprometimento do agente é em função do valor da recompensa recebida pelos objetivos alcançados (Podrug, Filipovic \& Milic, 2010).

\section{Planos de Opções de Ações}

O uso das opções ocorre desde as civilizações gregas e romanas, e o modelo atual foi desenvolvido nos Estados Unidos, após a crise de 1929 (Nunes, 2008). O registro mais antigo consta na Chrysler Corp, em que a primeira aprovação dos planos de outorga de opções pelo Conselho de Administração ocorreu em 1952 (Smith \& Wallace, 1997). Já no Brasil, os primeiros registros de planos de incentivo em opções de ações datam da década de 1970, utilizados por empresas norte-americanas instaladas no país (Nunes, 2008).

De acordo com Nunes (2008), o uso das opções de ações como forma de remuneração consiste em conceder, em uma data específica, opções para compra de lotes de ações da empresa no futuro, a um preço de exercício fixo, que seja igual, ou não, ao preço de mercado corrente na época da concessão. $\mathrm{O}$ autor menciona ainda que a utilização desse tipo de remuneração proporciona maior motivação para que os empregados das companhias se esforcem para melhorar o desempenho, que, consequentemente, resultará no aumento do valor das ações, excedendo-a do preço de exercício e proporcionando maior ganho.

Os planos de opções de ações, cada vez mais importantes na estrutura financeira das entidades, são opções pertinentes aos empregados, que obedecem a alguns requisitos: concedem aos empregados o direito de adquirir determinado ou determinável número de ações e de receber um certo montante variável com o preço das ações ou com o valor dos dividendos. Dessa forma, consideram-se as opções de ações uma retribuição da entidade aos funcionários (Tiscini \& Raoli, 2013).

Além de as entidades emitirem opções de ações para ajustarem os interesses dos gestores e dos acionistas, também são utilizadas como forma de remuneração aos empregados, atraindo-os e retendo-os, e, ainda, como instrumento de obtenção de rendimento de acionistas (Uchida, 2006; Cesari \& Ozkan, 2015). A atração e retenção dos funcionários ocorre porque ao desligar-se da organização, antes da posse das opções de ações, o empregado perde o direito sobre elas. Além disso, quando aceitam, os empregados se tornam acionistas da própria empresa em que trabalham (Tzioumis, 2008; Cesari \& Ozkan, 2015).

O marco regulatório do tema no mercado brasileiro ocorreu no ano de 2008, quando o Comitê de Pronunciamentos Contábeis (CPC) aprovou o Pronunciamento Técnico CPC 10 - Pagamento baseado em ações (Dias, 2010; Larini et al., 2015). 


\section{Fatores Determinantes para Adoção de Planos de Opções de Ações e Hipóteses da Pesquisa}

Diversos fatores são apontados na literatura como determinantes para a adoção de planos de opções de ações, como, por exemplo, tamanho da empresa (Ding \& Sun, 2001; Kato et al., 2005; Uchida, 2006; Chourou et al., 2008; Tzioumis, 2008; Dias, 2010); restrições de liquidez (Yermack, 1995; Bryan et al., 2000; Ding \& Sun, 2001; Uchida, 2006; Tzioumis, 2008; Dias, 2010); concentração acionária (Nagaoka, 2005; Banghoj et al., 2010; Dias, 2010) problema de horizonte (Bryan et al., 2000; Tzioumis, 2008; Dias, 2010); dualidade do cargo de CEO e presidente do conselho de administração (Tzioumis, 2008; Qin, 2012); e participação acionária do CEO (Kato et al., 2005; Uchida, 2006; Chourou et al., 2008; Tzioumis, 2008; Qin, 2012). Na sequência, descreve-se cada um deles, e as respectivas hipóteses de pesquisa.

\subsection{Tamanho da Empresa}

Em empresas maiores, de acordo com Ding e Sun (2001), é mais difícil controlar as ações do agente, se comparadas com empresas menores. Por isso, as grandes empresas têm maiores incentivos para adotar planos de opções de ações como alternativa para minimizar potenciais problemas de agência. Uchida (2006) apresenta argumentos semelhantes, pois, segundo ele, os gestores de grandes empresas devem alocar recursos mais complexos, por isso, torna-se mais difícil para os acionistas o monitoramento. Desse modo, a utilização de planos de opções de ações podem contribuir para um maior alinhamento entre principal e agente.

Além disso, grandes empresas tendem a realizar operações mais complexas, uma vez que possuem negócios em diferentes países e com diferentes tipos de empresas situadas em variadas regiões geográficas. Portanto, é plausível considerar que, além de atrair profissionais mais influentes e capacitados, essas empresas proporcionam melhores remunerações aos seus executivos, inclusive com utilização de planos de opções de ações (Kato et al., 2005; Chourou et al., 2008; Tzioumis, 2008). Tzioumis (2008), assim como Dias (2010) menciona que grandes empresas possuem maior capacidade financeira e, consequentemente, são aquelas com maiores possibilidades de remunerarem seus executivos com planos de opções de ações. Diante disso, estabelece-se a primeira hipótese de pesquisa:

$\mathrm{H}_{1}$ : O tamanho da empresa é um fator determinante para adoção de planos de opções de ações. Espera-se que empresas de maior porte tenham melhores condições e incentivos para adotarem planos de opções de ações.

\subsection{Restrições de Liquidez}

Outro motivo que pode contribuir para a adoção de planos de opções de ações como forma de remuneração do gestor, conforme descreve Tzioumis (2008), é a presença de restrições de liquidez da empresa, visto que as opções de ações não exigem um desembolso de caixa. $\mathrm{O}$ autor menciona ainda que as opções de ações podem servir como incentivo para que o gestor procure reverter a situação.

Os planos de opções de ações, para Ding e Sun (2001), são uma forma de remuneração "sem dinheiro" para os executivos, do ponto de vista dos acionistas. Os autores destacam ainda que os executivos irão injetar dinheiro na empresa, caso exerçam suas opções. Portanto, observam que empresas que enfrentam restrições de liquidez estarão mais propícias a adotarem os planos de opções de ações como forma de remuneração dos seus executivos. 
O mesmo pensamento também é preconizado por outros autores, tais como Yermack (1995), Bryan et al. (2000), Uchida (2006) e Dias (2010). Assim, estabeleceu-se a segunda hipótese:

$\mathrm{H}_{2}$ : Restrição de liquidez é um fator determinante para adoção de planos de opções de ações. Nessa direção, espera-se que empresas com restrições de liquidez estarão mais propensas à adoção de planos de opções de ações.

\subsection{Concentração Acionária}

Em algumas empresas, o acionista controlador detém grande percentual de participação acionária. Nesses casos, a concentração reduz o comportamento discricionário dos gestores, haja vista que grandes investidores visam à maximização do lucro da empresa e maior controle sobre os seus ativos para terem seus direitos respeitados (Nagaoka, 2005; Dias, 2010).

Grandes acionistas controladores, diferente de diversos acionistas dispersos, possuem maior acessibilidade às ações dos executivos, visto que possuem maiores incentivos econômicos para monitorar os gestores. Esses fatores, segundo Banghoj et al. (2010), reduzem a necessidade do pagamento de remuneração variável, principalmente aquelas baseadas em desempenho, caso dos planos de opções de ações.

Seguindo a linha de raciocínio que maior concentração de capital contribui para maior alinhamento dos interesses entre principal e agente, estabelece-se a terceira hipótese de pesquisa:

$H_{3}$ : A concentração acionária é um fator determinante para adoção de planos de opções de ações. Seguindo a linha de raciocínio de que maior concentração acionária contribui para maior alinhamento de interesses entre principal e agente, pode-se esperar que as empresas que possuem maior concentração acionária farão menor uso dos planos de opções de ações.

\subsection{Problema de Horizonte}

O problema de horizonte, segundo Tzioumis (2008), surge quando os CEOs se aproximam da aposentadoria. Isso ocorre, segundo o autor, porque o gestor passa a supervalorizar, na maioria das vezes, projetos que proporcionam resultados apenas em curto prazo, em vez de investimentos que possam aumentar a eficiência da empresa em longo prazo, como investimento em pesquisa e desenvolvimento, por exemplo.

Assim, os planos de opções de ações poderiam alterar o foco de curto prazo dos gestores próximos da aposentadoria e incentivar a busca por projetos e investimentos que favoreçam os interesses de longo prazo que os acionistas possuem (Bryan et al., 2000; Tzioumis, 2008; Dias, 2010).

Desse modo, em virtude da possibilidade de existência do problema de horizonte, foi estabelecido a quarta hipótese de pesquisa:

$\mathrm{H}_{4}$ : A idade do CEO é um fator determinante para adoção de planos de opções de ações. Espera-se que a maior idade do CEO influencie para que as empresas estejam mais propensas à adoção de planos de opções de ações. 


\subsection{Dualidade de Funções (Ceo e Presidente do Conselho de Administração)}

A dualidade, analisada nesse estudo, ocorre quando um indivíduo ocupa o cargo de diretor-presidente e de presidente do conselho de administração, ou seja, dois cargos de máxima relevância. Sob a abordagem da teoria da Agência, seria esperado que a separação das funções de presidente e CEO contribuiria para uma redução dos conflitos de agência (Qin, 2012). A não dualidade, conforme descreve Qin (2012), permite que o conselho de administração, como representante dos acionistas, monitore e controle, de forma mais eficaz, as ações dos executivos que atuam como diretores.

Além disso, ao comparar um CEO que não acumula o cargo de diretor executivo e de presidente do conselho de administração com um CEO que possui essa dupla responsabilidade, Tzioumis (2008) chama a atenção para o fato de que, quando essa dualidade de funções existe, o CEO enfrenta tarefas mais complexas. Observa, ainda, que maior responsabilidade e capacidade é exigida. Portanto, será necessário melhorar a remuneração do gestor.

Nesses casos, uma alternativa é aumentar a remuneração baseada no desempenho, incluindo no pacote de remuneração os planos de opções de ações. Assim, estabeleceu-se a quinta hipótese de pesquisa:

$\mathrm{H}_{5}$ : A dualidade do cargo de CEO e presidente do conselho de administração é um fator determinante para a adoção de planos de opções de ações. Espera-se que, empresas que possuem o mesmo indivíduo ocupando o cargo de diretor-presidente e de presidente do conselho de administração estarão mais propensas à adoção de planos de opções de ações.

\subsection{Participação Acionária do CEO:}

Na medida em que os gestores possuem ações da própria companhia em que atuam, eles arcarão com uma parte dos custos e apresentarão menor tendência a desperdiçar a riqueza da empresa (Morck, Shleifer \& Vishny, 1988). Logo, a adoção de planos de opções de ações poderá ser uma alternativa para alinhar o interesse do CEO ao dos demais acionistas e, dessa forma, minimizar potenciais problemas de agência (Kato et al., 2005; Uchida, 2006; Chourou et al., 2008; Qin, 2012).

Tzioumis (2008) esclarece que a participação acionária do CEO na empresa em que atua refere-se ao porcentual de ações que possui em relação ao total de ações em circulação e, também, apresenta argumentos semelhantes aos de Kato et al. (2005) e Chourou et al. (2008), de que os planos de opções de ações representam incentivos adicionais para o CEO buscar a maximização do valor da companhia e, por consequência, maximização da riqueza dos acionistas. Diante disso, estabelece-se a sexta hipótese de pesquisa:

$\mathrm{H}_{6}$ : A participação acionária do CEO é um fator determinante para a adoção de planos de opções de ações. Nessa direção, espera-se que empresas com participações acionárias do CEO estejam mais propensas à adoção de planos de opções de ações, pois essa ação proporcionará maior alinhamento de interesses. 


\section{Procedimentos Metodológicos}

Esta pesquisa, caracterizada como descritiva, foi realizada por meio de análise documental e abordagem quantitativa dos dados. A população objeto do estudo é composta pelas companhias listadas na Bolsa de Valores, Mercadorias e Futuros de São Paulo (BM\&FBOVESPA), em 16 de outubro de 2013. A amostra estudada compõe-se das companhias abertas participantes do Nível 1, Nível 2 e Novo Mercado da BM\&FBOVESPA, com exceção das empresas do setor financeiro e outros, que foram excluídas em virtude das peculiaridades do setor. Também foram excluídas as empresas que não possuíam dados para todas as variáveis em todos os anos analisados, totalizando assim, 158 companhias, das quais 24 estavam listadas no Nível 1; 14, no Nível 2; e 120 empresas, no Novo Mercado.

A escolha dessas companhias justifica-se pela representatividade que possuem em seus respectivos setores. Além disso, por participarem dos níveis diferenciados de governança corporativa, essas organizações estão sujeitas a um conjunto de práticas que visam ampliar os direitos dos acionistas, transmitir maior segurança e melhorar a qualidade das informações ao público.

Inicialmente, foram analisados os Formulários de referência, de cada uma das 158 companhias, para identificar aquelas que possuíam planos de opções de ações. Em seguida, foram coletados os dados dos fatores apontados na literatura como determinantes para a utilização de tais planos, como destacado no construto da pesquisa, apresentado no Quadro 2.

\begin{tabular}{|c|c|c|c|c|}
\hline \multirow{2}{*}{\multicolumn{2}{|c|}{ Variáveis }} & Descrição & \multirow{2}{*}{ Fonte de dados } & \multirow{2}{*}{ Autores } \\
\hline & & Como calcular & & \\
\hline 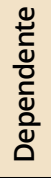 & $\begin{array}{l}\text { Plano de opção } \\
\text { de ação }\end{array}$ & $\begin{array}{l}\text { Empresa possui: } \\
\text { Não }=0 / \mathrm{Sim}=1\end{array}$ & $\begin{array}{l}\text { Formulário de Referência: } \\
\text { Seção } 13 \text { - Remuneração dos } \\
\text { administradores }\end{array}$ & $\begin{array}{l}\text { Ding e Sun (2001), Uchida } \\
\text { (2006), Dias (2010) }\end{array}$ \\
\hline \multirow{7}{*}{ 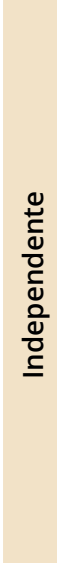 } & Tamanho & $\begin{array}{l}\text { Logaritmo neperiano } \\
\text { do Ativo total }\end{array}$ & Banco de dados Economática & $\begin{array}{l}\text { Ding e Sun (2001), Uchida } \\
\text { (2006), Tzioumis (2008) }\end{array}$ \\
\hline & \multirow{2}{*}{$\begin{array}{l}\text { Liquidez } \\
\text { corrente }\end{array}$} & Ativo circulante & \multirow{2}{*}{ Banco de dados Economática } & \multirow{2}{*}{$\begin{array}{l}\text { Ding e Sun (2001), } \\
\text { Tzioumis (2008) }\end{array}$} \\
\hline & & Passivo circulante & & \\
\hline & $\begin{array}{l}\text { Concentração } \\
\text { acionária }\end{array}$ & $\begin{array}{l}\text { \% Ações ordinárias em } \\
\text { posse do maior acionista }\end{array}$ & Banco de dados Economática & $\begin{array}{l}\text { Nagaoka (2005), Banghoj } \\
\text { et al. (2010), Dias (2010) }\end{array}$ \\
\hline & $\begin{array}{l}\text { Problema de } \\
\text { horizonte }\end{array}$ & Idade do CEO & $\begin{array}{l}\text { Formulário de Referência: } \\
\text { Seção } 12 \text { - Assembleia e administração }\end{array}$ & $\begin{array}{l}\text { Bryan et al. (2000), Tzioumis } \\
\text { (2008), Dias (2010) }\end{array}$ \\
\hline & $\begin{array}{l}\text { Dualidade de } \\
\text { funções }\end{array}$ & $\begin{array}{l}\text { Dualidade: } \\
\text { Não }=0 / \operatorname{Sim}=1\end{array}$ & $\begin{array}{l}\text { Formulário de Referência: } \\
\text { Seção } 12 \text { - Assembleia e administração }\end{array}$ & $\begin{array}{l}\text { Tzioumis (2008), } \\
\text { Chen e Lee (2010) }\end{array}$ \\
\hline & $\begin{array}{l}\text { Participação } \\
\text { acionária do CEO }\end{array}$ & $\begin{array}{l}\text { Possui: } \\
\text { Não = } 0 / \operatorname{Sim}=1\end{array}$ & $\begin{array}{l}\text { Formulário de Referência: } \\
\text { Seção } 13 \text { - Remuneração dos } \\
\text { administradores; Seção } 15 \text { - Controle }\end{array}$ & $\begin{array}{l}\text { Kato et al. (2005), } \\
\text { Chourou et al. (2008) }\end{array}$ \\
\hline
\end{tabular}

Quadro 1. Quadro das variáveis dependentes e independentes

Fonte: elaborado pelos autores.

Nota-se, no Quadro 2, que os dados relacionados ao tamanho, liquidez corrente e concentração acionária foram coletados no banco de dados Economática. Os dados referentes ao problema de horizonte, dualidade de funções e participação acionária do CEO foram coletados, manualmente, nos Formulários de Referência de cada uma das 158 companhias. O período de coleta e de análise corresponde aos anos de 2009 a 2012. 
Na sequência, realizaram-se os procedimentos estatísticos de análise multivariada de dados por meio da regressão logística. A regressão logística, de acordo com Hair, Anderson, Tatham e Black (2009, p. 34) - "[...] é a técnica multivariada adequada quando a única variável dependente é dicotômica", caso deste estudo, em que a variável dependente é representada pela adoção ou não a planos de opções de ações, com atribuição de valor " 0 " para as empresas que não possuíam os planos e "1" para aquelas que possuíam. Sendo assim, buscou-se verificar a associação da variável dependente/binária, adoção de planos de opções de ações com as diversas variáveis independentes apresentadas, por isso, definiu-se a regressão logística como técnica estatística apropriada.

\section{Descrição e Análise dos Dados}

Esta seção contém a descrição e análise dos dados coletados. Primeiramente, descreve-se o número de empresas que possuíam planos de opções de ações no período de 2009 a 2012. Na sequência, demonstram-se os resultados da regressão logística que possibilitaram alcançar o objetivo do estudo.

Inicia-se pela Tabela 1, expondo o total de empresas que possuíam planos de opções de ações, entre as 158 que compõem a amostra.

Tabela 1

Empresas que possuíam planos de opções de ações no período de 2009 a 2012

\begin{tabular}{|c|c|c|c|c|c|c|c|c|}
\hline \multirow{2}{*}{ Planos de opções de ações } & \multicolumn{2}{|c|}{2009} & \multicolumn{2}{|c|}{2010} & \multicolumn{2}{|c|}{2011} & \multicolumn{2}{|c|}{2012} \\
\hline & $\mathrm{N}^{\circ}$ & $\%$ & $\mathrm{~N}^{\circ}$ & $\%$ & $\mathrm{~N}^{\circ}$ & $\%$ & $\mathrm{~N}^{\circ}$ & $\%$ \\
\hline Utilizam & 77 & 49 & 89 & 56 & 105 & 66 & 112 & 71 \\
\hline Não utilizam & 81 & 51 & 69 & 44 & 53 & 34 & 46 & 29 \\
\hline Total de empresas & 158 & 100 & 158 & 100 & 158 & 100 & 158 & 100 \\
\hline
\end{tabular}

Fonte: dados da pesquisa.

Nota-se, analisando os dados da Tabela 1, que os planos de opções de ações ainda não recebiam a devida importância no meio empresarial, no ano de 2009. Isso, em razão da quantidade de empresas que possuíam os planos (49), somente $49 \%$ delas. No entanto, percebe-se um crescimento no número de empresas que adotaram tais planos, chegando a 71\%, em 2012.

Na sequência, realizou-se a regressão logística, com o objetivo de identificar os fatores determinantes para a adoção de planos de opções de ações nas companhias da amostra, sendo que o primeiro passo é demonstrar, por meio da Tabela 2, como seriam classificadas as empresas caso o modelo se deixasse guiar apenas em função dos enquadramentos observados. 
Tabela 2

Quadro de classificação anterior à análise de regressão logística

\begin{tabular}{|c|c|c|c|c|c|}
\hline \multicolumn{6}{|c|}{ Classification Table $(a, b)$} \\
\hline & \multirow{3}{*}{ Observed } & & \multicolumn{3}{|c|}{ Predicted } \\
\hline & & & \multicolumn{2}{|c|}{ Planos de Opções de Ações } & \multirow{2}{*}{ Percentage Correct } \\
\hline & & & Não possui & Possui & \\
\hline \multicolumn{6}{|c|}{ Painel A - 2009} \\
\hline \multirow[t]{3}{*}{ Step 0} & \multirow{2}{*}{ Planos de Opções de Ações } & Não possui & 81 & 0 & 0 \\
\hline & & Possui & 77 & 0 & 100 \\
\hline & Overall Percentage & & & & 51,30 \\
\hline \multicolumn{6}{|c|}{ Painel B - 2010} \\
\hline \multirow[t]{3}{*}{ Step 0} & \multirow{2}{*}{ Planos de Opções de Ações } & Não possui & 0 & 69 & 0 \\
\hline & & Possui & 0 & 89 & 100 \\
\hline & Overall Percentage & & & & 56,30 \\
\hline \multicolumn{6}{|c|}{ Painel C - 2011} \\
\hline \multirow[t]{3}{*}{ Step 0} & \multirow{2}{*}{ Planos de Opções de Ações } & Não possui & 0 & 53 & 0 \\
\hline & & Possui & 0 & 105 & 100 \\
\hline & Overall Percentage & & & & 66,50 \\
\hline \multicolumn{6}{|c|}{ Painel D - 2012} \\
\hline \multirow[t]{3}{*}{ Step 0} & \multirow{2}{*}{ Planos de Opções de Ações } & Não possui & 0 & 46 & 0 \\
\hline & & Possui & 0 & 112 & 100 \\
\hline & Overall Percentage & & & & 70,90 \\
\hline
\end{tabular}

Fonte: dados da pesquisa.

Nota-se, na Tabela 2, de acordo com os resultados gerados pelo software estatístico SPSS, que a amostra composta por 158 companhias teria uma pré-classificação de que todas as empresas estariam classificadas como possuindo planos de opções de ações em todos os anos analisados. Conforme descrevem Dias e Corrar (2009), significa que o modelo iria classificar corretamente as empresas que possuíam planos de opções de ações, mas incorretamente aquelas que não possuíam tais planos.

Nesta pesquisa, o percentual geral de acertos nas classificações seria de 51,30\%, em 2009, 56,30\%, em 2010, 66,50\%, em 2011 e 70,90\%, em 2012. Essa análise é importante, conforme descrevem Dias e Corrar (2009), pois serve como referência para avaliar a eficácia do modelo a partir do momento que ele passar a operar com as variáveis independentes.

Desse modo, espera-se que tais percentuais se elevem após a inclusão das variáveis independentes. $\mathrm{Na}$ Tabela 3, evidenciam-se as respectivas variáveis com os respectivos scores e níveis de significância dos períodos analisados. 
Tabela 3

Variáveis independentes da regressão logística do período de 2009 a 2012

\begin{tabular}{|c|c|c|c|c|c|c|c|c|}
\hline \multirow{2}{*}{ Variáveis } & \multicolumn{2}{|c|}{2009} & \multicolumn{2}{|c|}{2010} & \multicolumn{2}{|c|}{2011} & \multicolumn{2}{|c|}{2012} \\
\hline & Wald & Sig. & Wald & Sig. & Wald & Sig. & Wald & Sig. \\
\hline Tamanho (Ativo Total) & 0,3050 & 0,581 & 0,4220 & 0,516 & 0,1260 & 0,723 & 0,8070 & 0,369 \\
\hline Liquidez Corrente & 0,4060 & 0,524 & 6,5780 & $0,010 *$ & 0,7650 & $0,082 *$ & 3,3780 & $0,066 *$ \\
\hline Concentração acionária & 0,7950 & 0,389 & 0,8015 & 0,305 & 0,7265 & 0,346 & 0,7569 & 0,398 \\
\hline Problema de horizonte & 2,8390 & $0,092 *$ & 3,8230 & $0,051 *$ & 6,3670 & 0,010 * & 17,0910 & $0,000 * *$ \\
\hline Dualidade de funções & 0,0880 & 0,767 & 0,0250 & 0,875 & 0,2270 & 0,634 & 0,0030 & 0,958 \\
\hline Participação acionária do CEO & 0,4470 & 0,504 & 2,1910 & 0,139 & 2,4640 & 0,116 & 4,0220 & $0,045 * *$ \\
\hline
\end{tabular}

**Estatisticamente significativa ao nível de significância de 0,05.

*Estatisticamente significativa ao nível de significância de 0,10.

Fonte: dados da pesquisa.

Por meio da Tabela 3, nota-se que a variável "tamanho" não é estatisticamente significativa ao nível de $10 \%$, no período analisado. Portanto, foi rejeitada a hipótese $\mathrm{H}_{1}$, pois o resultado demonstra que o tamanho não pode ser considerado um fator determinante para a adoção de planos de opções de ações na amostra analisada. Sendo assim, não se confirmou o relato de Ding e Sun (2001), Kato et al. (2005), Uchida (2006), Chourou et al. (2008), Tzioumis (2008) e Dias (2010).

Observa-se ainda, na Tabela 3, que a variável "liquidez corrente" apresentou significância estatística ao nível de 0,10 para os anos de 2010, 2011 e 2012. Sendo assim, não foi possível rejeitar a hipótese $\mathrm{H}_{2}$, pois o resultado indica que as empresas com restrição de liquidez corrente eram aquelas que mais possuíam planos de opções de ações. Esse resultado coaduna com o descrito na literatura (Yermack, 1995; Bryan et al., 2000; Ding \& Sun, 2001; Uchida, 2006; Tzioumis, 2008; Dias, 2010), de que empresas que enfrentam restrições de liquidez estarão mais propícias a adotarem os planos de opções de ações como forma de remuneração dos seus executivos.

A variável "concentração acionária", assim como a variável "tamanho", também não apresentou significância estatística em nenhum dos anos analisados. Sendo assim, a hipótese $\mathrm{H}_{3}$ foi rejeitada, ou seja, para a amostra desta pesquisa, não se confirmou o que foi preconizado por Nagaoka (2005), Banghoj et al. (2010) e Dias (2010), que diziam que a concentração acionária pode influenciar na adoção de planos de opções de ações.

Nota-se, também, que a variável "problema de horizonte" apresentou significância estatística a um nível de $10 \%$, em todos os anos analisados. Dessa forma, não se rejeita a hipótese $\mathrm{H}_{4}$, já que o resultado evidencia que entre as empresas da amostra existe associação entre a idade do CEO e a adoção de planos de opções de ações, assim como preconizam Bryan et al. (2000), Tzioumis (2008) e Dias (2010).

Outra variável que apresentou significância estatística a um nível de $10 \%$ foi a variável "participação acionária do CEO", no entanto, somente para o ano de 2012. Portanto, a hipótese $\mathrm{H}_{6}$ não pôde ser rejeitada neste ano. Tal resultado indica, assim como nos estudos de Kato et al. (2005), Uchida (2006), Chourou et al. (2008) e Tzioumis (2008), que, no ano de 2012, a participação acionária do CEO tornou-se um dos fatores determinantes para a adoção dos planos de opções de ações.

Verifica-se ainda, na Tabela 3, que a variável "dualidade de funções" também não apresentou significância estatística. Sendo assim, a hipótese $\mathrm{H}_{5}$ foi rejeitada para as empresas analisadas, ou seja, para a amostra desta pesquisa, não se confirmou o relato de Tzioumis (2008), de que a dupla responsabilidade é um fator determinante para a adoção de planos de opções de ações.

Resumidamente, percebe-se que três variáveis demonstraram-se estatisticamente significativas, no mínimo, em um dos anos. Portanto, verifica-se que os fatores "liquidez corrente", no período de 2010 a 2012, "problema de horizonte", no período de 2009 a 2012, e "participação acionária", no ano de 2012, podem ser considerados determinantes para a adoção de planos de opções de ações entre as companhias abertas que compõem a amostra de pesquisa. 
Na sequência, por meio da Tabela 4, apresentam-se os testes Step, Block e Model, Hosmer \& Lemeshow e os indicadores -2LL, Cox-Snell $\mathrm{R}^{2}$ e Nagelkerke, que possibilitam analisar, após a inclusão das variáveis independentes, se os modelos podem ser considerados capazes de realizar as predições com a acurácia desejada.

Tabela 4

Testes para validação do modelo de regressão logística do período de 2009 a 2012

\begin{tabular}{|c|c|c|c|c|c|c|c|c|}
\hline & \multicolumn{2}{|l|}{2009} & \multicolumn{2}{|c|}{2010} & \multicolumn{2}{|c|}{2011} & \multicolumn{2}{|c|}{2012} \\
\hline \multicolumn{9}{|c|}{ Painel A - Omnibus Tests of Model Coefficients } \\
\hline & Chi-square & Sig. & Chi-square & Sig. & Chi-square & Sig. & Chi-square & Sig. \\
\hline Step & 3,981 & 0,552 & 15,472 & 0,009 & 11,322 & 0,045 & 30,143 & 0,000 \\
\hline Block & 3,981 & 0,552 & 15,472 & 0,009 & 11,322 & 0,045 & 30,143 & 0,000 \\
\hline Model & 3,981 & 0,552 & 15,472 & 0,009 & 11,322 & 0,045 & 30,143 & 0,000 \\
\hline \multicolumn{9}{|c|}{ Painel B - Model Summary } \\
\hline-2 Log likelihood & \multicolumn{2}{|c|}{214,9520} & \multicolumn{2}{|c|}{201,0250} & \multicolumn{2}{|c|}{190,2760} & \multicolumn{2}{|c|}{160,4580} \\
\hline Cox \& Snell R Square & \multicolumn{2}{|l|}{0,025} & \multicolumn{2}{|c|}{0,093} & \multicolumn{2}{|c|}{0,069} & \multicolumn{2}{|c|}{0,274} \\
\hline Nagelkerke R Square & \multicolumn{2}{|l|}{0,033} & \multicolumn{2}{|c|}{0,125} & \multicolumn{2}{|c|}{0,096} & \multicolumn{2}{|c|}{0,348} \\
\hline \multicolumn{9}{|c|}{ Painel C - Hosmer and Lemeshow Test } \\
\hline Step & Chi-square & Sig. & Chi-square & Sig. & Chi-square & Sig. & Chi-square & Sig. \\
\hline 1 & 11,628 & 0,169 & 10,317 & 0,243 & 13,558 & 0,194 & 11,902 & 0,156 \\
\hline
\end{tabular}

*Estatisticamente significativa ao nível de significância de 0,010.

Fonte: dados da pesquisa.

Os testes Step, Block e Model objetivam demonstrar a capacidade preditiva do modelo. Os resultados, descritos no Painel A, da Tabela 4, foram de 3,981, para o ano de 2009; 15,472, para 2010;11,322, para 2011; e 30,143, para o ano de 2012. Cabe destacar que, no ano de 2009, os coeficientes Step, Block e Model não são estatisticamente significativos ao nível de significância de 5\%, ou seja, nesse ano não houve melhorara significante na qualidade das predições após a inclusão das variáveis independentes. Esse resultado deve-se, principalmente, porque, no ano de 2009 (Tabela 3), somente uma das 6 variáveis foi significativa.

Verifica-se ainda, no Painel B, da Tabela 4, um valor para-2Log likelihood de 214,952, em 2009; de 201,025, em 2010; 190,276, em 2011; e de 160,458, em 2012, ou seja, decrescente. Esses resultados indicam que o poder explicativo do modelo aumenta no decorrer dos anos, pois, de acordo com Dias e Corrar (2009), quanto menor o indicador, maior será o poder preditivo do modelo.

O teste Cox \& Snell e Nagelkerke são considerados Pseudos-R-Quadrado e se assemelham ao coeficiente de determinação $\mathrm{R}^{2}$, utilizados no modelo linear, conforme descrevem Dias e Corrar (2009). Portanto, os dois indicadores, nesta pesquisa, refletem que as variações ocorridas no $\log$ da razão da variável dependente (adoção de planos de opções de ações) não podem ser explicadas de modo satisfatório pelo conjunto das variáveis independentes (fatores determinantes dos planos de opções de ações). Destaca-se que $\mathrm{o}$ ano de 2012 possui os melhores resultados nesses indicadores, principalmente, porque, nesse ano 2012 (Tabela 3), três variáveis, entre as seis analisadas, foram significativas.

Por último, o teste Hosmer e Lemesshow, que visa, também segundo Dias e Corrar (2009), testar a hipótese de que não ocorrem diferenças significativas entre o que foi predito e o observado pelo modelo, resultou em valores sem significância estatística em todos os anos. Nesse caso, esse resultado indica que os valores preditos não foram significativamente diferentes dos observados. Portanto, o teste Hosmer e Lemesshow demonstra que os modelos são adequados para verificar se os fatores analisados são determinantes para a adoção de planos de opções de ações.

$\mathrm{Na}$ Tabela 5, demonstra-se o percentual de acertos nas classificações após a inclusão das variáveis independentes. 
Tabela 5

Quadro de classificação final da análise de regressão logística do período de 2009 a 2012

\begin{tabular}{|c|c|c|c|c|c|}
\hline \multicolumn{6}{|c|}{ Classification Table $(a, b)$} \\
\hline & \multirow{3}{*}{ Observed } & & \multicolumn{3}{|c|}{ Predicted } \\
\hline & & & \multicolumn{2}{|c|}{ Planos de Opções de Ações } & \multirow{2}{*}{ Percentage Correct } \\
\hline & & & Não possui & Possui & \\
\hline \multicolumn{6}{|c|}{ Painel A - 2009} \\
\hline \multirow[t]{3}{*}{ Step 0} & \multirow{2}{*}{ Planos de Opções de Ações } & Não possui & 55 & 26 & 67,90 \\
\hline & & Possui & 40 & 37 & 48,10 \\
\hline & Overall Percentage & & & & 58,20 \\
\hline \multicolumn{6}{|c|}{ Painel B - 2010} \\
\hline \multirow[t]{3}{*}{ Step 0} & \multirow{2}{*}{ Planos de Opções de Ações } & Não possui & 30 & 39 & 43,50 \\
\hline & & Possui & 24 & 65 & 73,00 \\
\hline & Overall Percentage & & & & 60,10 \\
\hline \multicolumn{6}{|c|}{ Painel C - 2011} \\
\hline \multirow[t]{3}{*}{ Step 0} & \multirow{2}{*}{ Planos de Opções de Ações } & Não possui & 12 & 41 & 22,60 \\
\hline & & Possui & 5 & 100 & 95,20 \\
\hline & Overall Percentage & & & & 70,90 \\
\hline \multicolumn{6}{|c|}{ Painel D - 2012} \\
\hline \multirow[t]{3}{*}{ Step 0} & \multirow{2}{*}{ Planos de Opções de Ações } & Não possui & 17 & 29 & 37,00 \\
\hline & & Possui & 8 & 104 & 92,90 \\
\hline & Overall Percentage & & & & 76,60 \\
\hline
\end{tabular}

Fonte: dados da pesquisa.

É possível perceber, na Tabela 5, que, após a inclusão das variáveis independentes, os percentuais de acerto do modelo, que antes eram de 51,33\%, em 2009; 56,30\%, em 2010; 66,50\%, em 2011; e 70,90\%, em 2012 (resultados apresentados na Tabela 2), elevaram-se para 58,20\%, 60,10\%, 70,90\% e 76,60\%, respectivamente, conforme é possível visualizar nos painéis $\mathrm{A}, \mathrm{B}, \mathrm{C}$ e $\mathrm{D}$ da Tabela 5.

No ano de 2009 (Painel A), ao analisar as 81 companhias que não possuíam planos de opções de ações, nota-se que $67,90 \%$ estariam classificadas corretamente. Em relação às 77 companhias que possuíam os planos, verifica-se que o percentual de acerto, após a inclusão das variáveis independentes, é equivalente a $48,10 \%$.

Em 2010 (Painel B), verifica-se que, das 69 companhias que não possuíam planos de opções de ações, 43,50\% estariam classificadas corretamente. Quanto às 89 companhias que possuíam os planos, constata-se que o percentual de acerto, após a inclusão das variáveis independentes, é de $73 \%$.

No ano de 2011 (Painel C), entre as 53 companhias que não possuíam planos de opções de ações, apenas $22,60 \%$ estariam classificadas corretamente. Por outro lado, das 105 companhias que possuíam os planos, verifica-se que o percentual de acerto após a inclusão das variáveis independentes é de 95,20\%.

Por fim, no ano de 2012 (Painel D), nota-se que, das 46 companhias que não possuíam planos de opções de ações, $37 \%$ estariam classificadas corretamente. Em relação às 112 companhias que possuíam os planos, constata-se que o percentual de acerto, após a inclusão das variáveis independentes, é de 92,90\%.

Portanto, ao considerar esses resultados, é possível afirmar, estatisticamente, que os fatores "liquidez corrente", no período de 2010 a 2012, "problema de horizonte", no período de 2009 a 2012, e "participação acionária", no ano de 2012, podem ser considerados determinantes para a adoção de planos de opções de ações entre as companhias abertas brasileiras listadas nos níveis diferenciados de governança corporativa da BM\&FBOVESPA que compõem a amostra de pesquisa. 


\section{Considerações Finais}

O objetivo do estudo foi identificar os fatores determinantes para a adoção de planos de opções de ações em companhias abertas brasileiras. Para tal, realizou-se pesquisa descritiva, conduzida por meio de análise documental e abordagem quantitativa, com emprego de regressão logística. A amostra foi composta por 158 companhias, com dados referentes ao período de 2009 a 2012, obtidos por meio dos Formulários de Referência e do Banco de dados Economática.

Os resultados evidenciaram que os planos de opções de ações ainda não recebem a devida importância no meio empresarial. Todavia, percebeu-se um crescimento na quantidade de empresas que adotaram tais planos no período de 2009 a 2012. Destacou-se, no período, o ano de 2012, com o maior número de empresas que possuíam planos, ou seja, 112 (71\%) dentre as 158 analisadas. Negativamente, destacou-se o ano de 2009, em que apenas 77 empresas (49\%) possuíam planos de opções de ações.

A regressão logística revelou que a variável "liquidez corrente" apresentou significância estatística para os anos de 2010, 2011 e 2012. Sendo assim, não foi possível rejeitar a hipótese $\mathrm{H}_{2}$, já que o resultado indicou que as empresas com restrição de liquidez corrente eram aquelas que mais possuíam planos de opções de ações. Esse resultado coaduna com o descrito na literatura (Yermack, 1995; Bryan et al., 2000; Ding \& Sun, 2001; Uchida, 2006; Tzioumis, 2008; Dias, 2010), de que empresas que enfrentam restrições de liquidez estarão mais propícias a adotarem os planos de opções de ações como forma de remuneração dos seus executivos.

Verificou-se também que a variável "problema de horizonte" apresentou significância estatística em todos os anos analisados. Dessa forma, não se rejeitou a hipótese $\mathrm{H}_{4}$, já que o resultado evidenciou que, entre as empresas da amostra, existia associação entre a idade do CEO e a adoção de planos de opções de ações, assim como preconizam Bryan et al. (2000), Tzioumis (2008) e Dias (2010).

Outra variável que apresentou significância estatística foi a variável "participação acionária do CEO", mas, somente para o ano de 2012. Nesse caso, a hipótese $\mathrm{H}_{6}$ não pôde ser rejeitada nesse ano. Tal resultado indicou, assim como nos estudos de Kato et al. (2005), Uchida (2006), Chourou et al. (2008) e Tzioumis (2008), que, no ano de 2012, a participação acionária do CEO era um dos fatores determinantes para a adoção dos planos de opções de ações.

Portanto, conclui-se que os fatores "liquidez corrente", no período de 2010 a 2012, "problema de horizonte" no período de 2009 a 2012, e "participação acionária", no ano de 2012, podem ser considerados determinantes para a adoção de planos de opções de ações entre as companhias abertas que compõem a amostra de pesquisa.

Essas descobertas forneceram mais evidências, para o cenário brasileiro, de relações positivas entre: "liquidez corrente" e adoção de planos de opções de ações (Yermack, 1995; Bryan et al., 2000; Ding \& Sun, 2001; Uchida, 2006; Tzioumis, 2008; Dias, 2010); "problema de horizonte" e adoção de planos de opções de ações (Bryan et al., 2000; Tzioumis, 2008; Dias, 2010); e "participação acionária" e adoção de planos de opções de ações (Kato et al., 2005; Uchida, 2006; Chourou et al., 2008; Tzioumis, 2008; Qin, 2012).

De modo contrário, verificou-se que a variável "tamanho" não foi estatisticamente significativa e, portanto, foi rejeitada a hipótese $\mathrm{H}_{1}$. Sendo assim, não se confirmou o relato de Ding e Sun (2001), Kato et al. (2005), Uchida (2006), Chourou et al. (2008), Tzioumis (2008) e Dias (2010). Uma possível justificativa é de que as empresas maiores têm habilidades superiores para introduzir outros dispositivos de governança, também capazes de minimizar potenciais problemas de agência.

A variável "concentração acionária" também não apresentou significância estatística em nenhum dos anos analisados. Sendo assim, a hipótese $\mathrm{H}_{3}$ foi rejeitada, ou seja, para a amostra desta pesquisa, não se confirmou o que foi preconizado por Nagaoka (2005), Banghoj et al. (2010) e Dias (2010). Uma justificativa para esse resultado recai no fato de que, no Brasil, a propriedade concentrada é a estrutura predominante na maioria das empresas e, por isso, não influencia na adoção de planos de opções de ações. 
Constatou-se ainda que a variável "dualidade de funções" não apresentou significância estatística. Sendo assim, a hipótese $\mathrm{H}_{5}$ foi rejeitada para as empresas analisadas. Desse modo, não se confirmou o relato de Tzioumis (2008) de que a dupla responsabilidade é um fator determinante para a adoção de planos de opções de ações. Uma justificativa para esse resultado é que as empresas não veem os planos de opções de ações como forma de monitorar os gestores que possuem dualidade de funções.

Destaca-se que o tema é de extrema importância e apresenta discussão crescente no meio acadêmico; merece destaque; e acerca dos resultados encontrados, provocaram interesse para futuras pesquisas. Assim, sugere-se acompanhar a utilização dos planos de opções de ações, não apenas nas empresas listadas nos níveis diferenciados de governança, mas também nas empresas do mercado tradicional. Também seria interessante verificar se o setor de atuação interfere nos resultados encontrados, além de outros períodos de tempo e outros fatores não utilizados neste estudo.

\section{Referências}

Arrow, K. J. (1985). The economics of agency. In J. Pratt, R. Zeckhauser (Eds.). Principals and agents: the structure of business. Boston: Harvard Business School Press.

Banghoj, J., Gabrielsen, G., Petersen, C., \& Plenborg, T. (2010). Determinants of executive compensation in privately held firms. Accounting \& Finance, 50(3), pp. 481-510. doi: 10.1111/j.1467$-629 X .2009 .00335 . x$.

Bergen, M., Dutta, S., \& Walker, O. (1992). Agency Relationships in Marketing: A Review of the Implications and Applications of Agency and Related Theories. Journal of Marketing, 56(3), pp. 1-24. doi:1. Retrieved from http://www.jstor.org/stable/1252293 doi:1

Bryan, S., Hwang, L., \& Lilien, S. (2000). CEO Stock-Based Compensation: An Empirical Analysis of Incentive-Intensity, Relative Mix, and Economic Determinants. The Journal of Business, 73(4), pp. 661-693.

Cesari, A., \& Ozkan, N. (2015). Executive incentives and payout policy: Empirical evidence from Europe. Journal of Banking \& Finance, 55, pp. 70-91. doi: http://dx.doi.org/10.1016/j.jbankfin.2014.12.011

Chen, Y. R., \& Lee, B. S. (2010). A dynamic analysis of executive stock options: Determinants and consequences. Journal of Corporate Finance, 16(1), pp. 88-103.

Chourou, L., Abaoub, E., \& Saadi, S. (2008). The economic determinants of CEO stock option compensation. Journal of Multinational Financial Management, 18(1), pp. 61-77.

Dias, J. M., Filho; Corrar, L. J. (2009). Regressão Logística. In: Corrar, L. J., Paulo, E., \& Dias, J. M., Filho (Org). Análise multivariada: para os cursos de administração, ciências contábeis e economia. São Paulo: Atlas.

Dias, W. O. (2010). Remuneração variável nas empresas brasileiras: estudo de determinantes da utilização de stock options. Dissertação de Mestrado, Universidade Federal de Minas Gerais, Belo Horizonte, MG, Brasil.

Dias, W. O., Cunha, J. V. A., \& Mário, P. C. (2009). Plano de incentivo em opções de ações e a harmonização contábil: estudo do nível de disclosure das empresas brasileiras após o CPC 10. Pensar Contábil, 11(46), pp. 29-38.

Ding, D. K., \& Sun, Q. (2001). Causes and effects of employee stock option plans: Evidence from Singapore. Pacific-Basin Finance Journal, 9(5), pp. 563-599. doi: 10.1016/S0927-538X(01)00027-0

Eisenhardt, K. M. (1989). Agency theory: An assessment and review. Academy of management review, 14(1), pp. 57-74. doi: 10.5465/AMR.1989.4279003 
Fama, E. F., \& Jensen, M. C. (1983). Separation of ownership and control. The Journal of Law \& Economics, 26(2), pp. 301-325.

Galdi, F. C., \& Carvalho, L. N. (2006) Remuneração em opções de ações: o SFAS 123 revisado. Revista Contabilidade e Finanças, Edição Comemorativa, pp. 23-35. doi: http://dx.doi.org/10.1590/S151970772006000400003

Hair Júnior., J. F., Anderson, R. E., Tatham, R. T., \& Black, W. C. (2009). Análise Multivariada de Dados. $8^{\mathrm{a}}$ ed. Porto Alegre: Bookman.

Jensen, M. C., \& Meckling, W. H. (1976). Theory of the firm: Managerial behavior, agency costs and ownership structure. Journal of financial economics, 3(4), pp. 305-360.

Kato, H. K., Lemmon, M., Luo, M., \& Schallheim, J. (2005). An empirical examination of the costs and benefits of executive stock options: Evidence from Japan. Journal of Financial Economics, 78(2), pp. 435-461. doi: doi:10.1016/j.jfineco.2004.09.001

Larini, A. M., Schafer, J. D., Rosa, P. A., \& Ferreira, L. F. (2015). Remuneração variável baseada no pagamento de ações: Um estudo de evidenciação das informações requeridas pelo CPC 10 (R1) aplicado em empresas brasileiras. Race: revista de administração, contabilidade e economia, 14(2), pp. 737-768. doi: 10.18593/race.v14i2.5896

Miranda, K. F., Tomé, W. C., \& Gallon, A. V. (2011). Evidenciação da remuneração variável nas melhores empresas para se trabalhar listadas na BM\&FBOVESPA: um estudo à luz dos CPCs 10 e 33. Pensar Contábil, 13(51), pp. 35-47.

Morck, R., Shleifer, A., \& Vishny, R. W. (1988). Management ownership and market valuation: An empirical analysis. Journal of financial economics, 20(1), pp. 293-315.

Nagaoka, S. (2005). Determinants of the introduction of stock options by Japanese firms: Analysis from the incentive and selection perspectives. The Journal of Business, 78(6), pp. 2289-2316.

Niyama, J. K., Campos, E. S., Gonçalves, R. L., \& da Silva Campos, G. P. (2012). Reconhecimento, Mensuração e Evidenciação de Operações de Remunerações em Opções de Ações de Companhias Abertas Listadas nos Segmentos Especiais de Governança Corporativa pela BM\&FBOVESPA. Contabilidade Vista \& Revista, 23(3), pp. 49-72.

Nunes, A. D. A. (2008). Concessão de opções de ações a funcionários: um problema contábil. Pensar Contábil, 10(40), pp. 109-129.

Perobelli, F. F. C., Lopes, B. S., \& Silveira, A. D. M. (2012). Planos de Opções de Compra de Ações e o Valor das Companhias Brasileiras. Revista Brasileira de Finanças, 10(1), p. 105-147.

Podrug, N., Filipovic, D., \& Milic, S. (2010). Critical overview of agency theory. Annals of DAAAM \& Proceedings, pp 1227-1229.

Qin, B. (2012). The influence of firm and executive characteristics on performance-vested stock option grants. International Business Review, 21(5), pp. 906-928. doi: 10.1016/j.ibusrev.2011.10.004

Ross, S. A. (1973). The economic theory of agency: The principal's problem. The American Economic Review, 63(2), pp. 134-139.

Siffert, N., Filho. (1996). A teoria dos contratos econômicos e a firma. São Paulo: IE/USP/Departamento de Economia.

Smith, K. J., \& Wallace, W. A. (1997). Instructional Case: Chrysler's Historical. Issues in Accounting Education, 12(2), pp. 457-495. 
Tannuri, G., Farias, S., Vicente, E. F. R., Van Bellen, H. M., \& Alberton, L. (2012). Uma Avaliação dos Efeitos dos Sistemas de Incentivos no Desempenho Econômico das Empresas Listadas no IBRX50 da BM\&FBOVESPA. Revista Contabilidade e Controladoria, 5(1), pp. 8-27. doi: http://dx.doi. org/10.5380/rcc.v5i1.27292

Tipuric, D. (2008). Agency Theory and Corporate Governance. Sinergija nakladništvo doo.

Tiscini, R., \& Raoli, E. (2013). Stock option plan practices in family firms: The idiosyncratic private benefits approach. Journal of Family Business Strategy, 4(2), pp. 93-105. doi:10.1016/j.jfbs.2013.03.001

Tzioumis, K. (2008). Why do firms adopt CEO stock options? Evidence from the United States. Journal of Economic Behavior \& Organization, 68(1), pp. 100-111. Doi: 10.1016/j.jebo.2007.06.008.

Uchida, K. (2006). Determinants of stock option use by Japanese companies. Review of Financial Economics, 15(3), pp. 251-269. http://doi.org/10.5651/jaas.20.27

Wood, T., Jr. \& Picarelli, V., Filho (2004). Remuneração estratégica: a nova vantagem competitiva (3a ed.). São Paulo: Atlas.

Yermack, D. (1995). Do corporations award CEO stock options effectively?. Journal of financial economics, 39(2), pp. 237-269. doi:10.1016/0304-405X(95)00829-4 